\title{
Kennedy space center cardiovascular disease risk reduction program evaluation
}

\author{
Kristine S Calderon' \\ Charles Smallwood' \\ David A Tipton ${ }^{2}$ \\ 'Occupational Medicine and \\ Environmental Health Services, \\ Comprehensive Health Services, \\ Inc., Kennedy Space Center, Kennedy \\ Space Center, FL, USA; ${ }^{2}$ Aerospace \\ Medicine and Occupational Health \\ Branch, National Aeronautics and \\ Space Administration, Kennedy Space \\ Center, FL, USA
}

\begin{abstract}
This program evaluation examined the Kennedy Space Center (KSC) Cardiovascular Disease (CVD) Risk Reduction Program which aims to identify CVD risk factors and reduce these risk factors through health education phone counseling. High risk participants (those having two or more elevated lipid values) are identified from monthly voluntary CVD screenings and counseled. Phone counseling consists of reviewing lab values with the participant, discussing dietary fat intake frequency using an intake questionnaire, and promoting the increase in exercise frequency. The participants are followed-up at two-months and five-months for relevant metrics including blood pressure, weight, body mass index (BMI), total cholesterol, high density lipoprotein (HDL) and low density lipoprotein (LDL) cholesterol, triglycerides, dietary fat intake, and exercise frequency. Data for three years of the KSC CVD Program included 366 participants, average age of 49 years, $75 \%$ male, and $25 \%$ female. For those with complete two and five month follow-up data, significant baseline to two-month follow-up comparisons included decreases in systolic blood pressure $(p=0.03)$; diastolic blood pressure $(p=0.002)$; total cholesterol, LDL cholesterol and dietary fat intake (all three at $p<0.0001$ ) as well as a significant increase in exercise frequency $(p=0.04)$. Significant baseline to five-month follow-up comparisons included decreases in triglycerides $(\mathrm{p}=0.05)$; and total cholesterol, LDL cholesterol and dietary intake (all three at $\mathrm{p}<0.0001$ ). These program evaluation results indicate that providing brief phone health education counseling and information at the worksite to high risk CVD participants may impact CVD risk factors.
\end{abstract}

Keywords: cardiovascular disease, counseling, worksite health, health education

\section{Introduction}

An estimated 79,400,000 American adults (one in three) have one or more types of cardiovascular disease (CVD) including high blood pressure, coronary heart disease (CHD), heart failure, and stroke (AHA 2007). CVD deaths account for one in every 2.8 deaths in the U.S. (Minino et al 2006). In terms of cost, the estimated direct and indirect cost of CVD in the US for 2007 is $\$ 431.8$ billion (AHA 2007). For worksites, previous research has shown that four of the top ten most costly physical health conditions affecting US employers (angina, hypertension, diabetes, and acute myocardial infarction) are related to heart disease and stroke (Goetzel et al 2003).

CHD, in particular, is the single largest killer of American males and females. About 38 percent of the people who experience a coronary heart attack in a given year will die from it (AHA 2007). A study of men and women in three prospective cohort studies found that about $90 \%$ of CHD patients have prior exposure to at least one of the following risk factors: high total blood cholesterol levels, hypertension, current cigarette use, and clinical report of diabetes (Greenland et al 2003). Much of the burden of CHD could be eliminated by reducing and controlling major risk factors such as high blood pressure, high blood cholesterol, physical inactivity and poor diet (Greenland et al 2003).
Correspondence: Kristine S Calderon CHS-005, Kennedy Space Center, FL 32899, USA

$\mathrm{Tel}+\mid$ 32I $86734 \mid 4$

Fax +I 32I 8677050

Email kristine.calderon@jbosc.ksc.nasa. gov 
Matson-Koffman and colleagues (2005) conducted an extensive review of worksite studies and interventions and concluded that comprehensive worksite health-promotion programs can have a great impact on heart disease and stroke and are likely to reduce employers' health and productivityrelated costs. Specifically, Pelletier (2001) reported on 120 health-enhancement studies, including 12 multi-component cardiovascular risk management worksite programs, which consistently showed positive clinical and cost outcomes. Moreover, randomized controlled trials (RCTs) suggest that individual risk reduction counseling and follow-up for high risk employees, within the context of a comprehensive multi-component program, may be the critical component for an effective worksite health promotion program (Heaney and Goetzel 1997).

In terms of worksite screening programs, such as cardiovascular disease screening, many studies have shown that effective individual risk factor follow-up education and counseling after screening contributed most to helping individuals control their risk factors, such as blood pressure, cholesterol, and smoking (Erfurt et al 1991; Erfurt and Holtyn 1991; Shi 1992; Gomel et al 1993; Larsen and Simons 1993; Fries et al 1994; Fielding et al 1995; Leutzinger et al 1995; Goetzel et al 1998; Ozminkowski et al 2000; Muto and Yamauchi 2001; Nilsson et al 2001). However, many worksite studies fail to provide detailed methodology regarding implementation or content covered in such follow-up counseling. Many worksite programs also fail to conduct follow-up screenings for program evaluation outcome measures and few studies have reported specifically on the use of follow-up telephonic counseling for changing CVD risk factor behaviors such as dietary fat intake and physical activity promotion.

The Kennedy Space Center (KSC) CVD Risk Reduction Program aims to identify CVD risk factors and reduce these risk factors through health education telephonic counseling. The purpose of this worksite program evaluation was to examine existing data from the KSC CVD Risk Reduction Program to determine if CVD risk factors such as blood lipid levels and health behaviors such as dietary fat intake and exercise frequency are improved.

\section{Methods}

The Kennedy Space Center is located near Cape Canaveral, Florida and employs approximately 15,000 civil servant and contractor employees. The Center offers comprehensive occupational health services including preventive health through three Center clinics. Services are free to all resident employees.
This program evaluation examined available program counseling data from May 2004 to May 2007. This voluntary program is open to all spaceport employees. Since this is an examination of existing program data and not a proposed research study, program participants were not required to complete informed consent nor be recruited for participation in the existing program. The examination (analysis) of existing program data however, was submitted to and approved by the KSC Human Subjects Institutional Review Board.

\section{KSC CVD program methods}

Monthly CVD screenings are held at two KSC clinics and are open to all KSC employees (both contractor and civil servant). The screenings are offered each month during the same time frame in the morning (7-9 am). Participants must fast for 12 hours prior to screening consuming no food or drink with the exception of water. If participants are taking medications, they are instructed to take them as normal with water. Screenings are performed by KSC occupational health staff including nurses and laboratory technicians. Participants complete screening forms, have their blood pressure taken and blood drawn to be analyzed for a lipid panel. Results are then sent confidentially to participants in the form of a risk factor profile letter including lab value delineation into normal, borderline, and high risk categories according to the Adult Treatment Panel (ATP) III guidelines (NCEP 2002).

After all screening data is entered and results are sent to employees, high risk participants are identified from the data as those having two or more lipid values falling into the high risk categories according to the ATP III Guidelines. These guidelines include total cholesterol $240 \mathrm{mg} / \mathrm{dL}$ or greater; LDL cholesterol $160 \mathrm{mg} / \mathrm{dL}$ or greater; HDL cholesterol $\mathrm{mg} / \mathrm{dL}$ or less; and triglycerides $200 \mathrm{mg} / \mathrm{dL}$ or greater. The high risk participants are then called via phone for counseling (as described below) and provided educational information (sent via intra-center mail) approximately one week after screening. The participants are followed-up at two-months and five-months thereafter via a letter reminding them to come to the clinics again for re-screening. Participation in this worksite program is completely voluntary and high risk counseled participants are not required to return to the clinics for follow-up.

\section{Health education phone counseling}

High risk CVD participants are contacted via phone during their work shift for health education counseling. Only one counseling phone call is made to each high risk participant 
and which lasts approximately 10-20 minutes depending on questions from the participant. The phone counseling call includes three components: a review of lipid results, an assessment of dietary fat intake and recommendations for dietary improvement and a discussion of personal exercise frequency. Each of these phone counseling components is described below. If the participant is a smoker, the staff notifies them of the worksite smoking cessation program. This notification does not occur often however, since historically only a small percentage of program participants are smokers (reported in "Results" section below). In addition, participants are asked if they are taking cholesterollowering medications. Blood pressure screening values are not addressed in the phone counseling.

For the first counseling component, the health promotion staff explains each lab value result to ensure the participant understands what each lipid value means including total cholesterol, HDL and LDL cholesterol, and triglycerides. The staff offers potential reasons as to why values may be elevated (eg, high saturated fat intake). Participants are then encouraged to share the CVD results with their private primary care providers.

Second, dietary fat is assessed by asking the participants dietary fat intake frequency questions from the MEDFICTS (Meats-Eggs-Dairy-Fried Foods-In baked goods-Convenience foods-Table fats-Snacks) Dietary Assessment Questionnaire (Kris-Etherton et al 2001) (eg, "How many times per week do you eat beef and pork?"). The MEDFICTS has been reported to be a quick, efficient tool that can be used in CVD screening, clinical practice or research. MEDFICTS has been validated in a study using computer-analyzed sets of 4-day food records randomly selected from 7-day food records resulting in significant pearson correlation coefficients between MEDFICTS and the 4-day records for percent energy from total fat $(\mathrm{r}=0.81, \mathrm{p}<0.0002)$; saturated fat $(\mathrm{r}=0.79, \mathrm{p}<0.0003)$; and cholesterol $(\mathrm{r}=0.52, \mathrm{p}<0.039)$ (Kris-Etherton et al 2001). Weekly fat consumption frequency is obtained for each of the 20 items in the 10 dietary fat food categories. The original MEDFICTS also includes a serving size question (indicating small, medium or large serving) for each item; however, asking these questions increases the length of time for questioning and are not used in the dietary fat intake for program participants. A score of " 1 " is assigned for frequency consumption of rarely/never, " 2 " for 3 times/week or less, and " 3 " for 4 times/week or more for high fat items (Group 1) in each food category. Low-fat items (Group 2) in each food category are reversed scored. Hence, the total dietary fat intake frequency scores range from 20 - low fat intake frequency to 60 - high fat intake frequency. Once these dietary questions are answered, the staff identifies frequently consumed high saturated and trans-fatty foods and makes recommendations for substitutions (eg, eat more fish and lean poultry; switch to low-fat dairy products).

Lastly, the staff inquires about the physical activity status that the participant indicates on his/her screening form by asking them what they are currently doing in terms of exercise. The KSC/NASA Physical Activity Status Scale, modified from the NASA Activity Scale (NAS) (Wier et al 2001), is included on the CVD screening forms. The NAS has been used in several exercise studies by the Johnson Space Center. In one study with men, the zero-order correlations between peak oxygen uptake and percentage body fat $(\mathrm{r}=-0.62)$ and NAS $(\mathrm{r}=0.58)$ were significant $(\mathrm{p}<0.05)$ (Jackson et al 1995). In a follow-up study with women, the zero-order correlations between peak oxygen uptake and $\%$ body fat $(r=-0.742)$ and NAS $(r=0.626)$ were also significant $(\mathrm{p}<0.05)$ (Jackson et al 1996). In terms of scale validation, both these studies indicate that self-report exercise from the NAS was related to actual physiological measures among participants. In the scale, participants are asked one question, "Check the box next to one of the following responses that best describes your exercise habits." The scale ranges from a score of " 0 " - no regular exercise/no physical activity outside of office work to "10" - regular exercise/weekly average of more than 11 hours per week (see Table 1). Participants with low status scores are encouraged to increase exercise frequency. Educational information regarding saturated and trans-fat substitutions and ways to increase physical activity is then sent to each participant via intra-center mail.

All program metrics are collected at the time of followup screening except for dietary fat intake. Participants must voluntarily bring in or mail in a completed set of the same MEDFICTS dietary fat frequency questions that were asked during baseline phone counseling for data to be gathered. This question set is mailed along with the follow-up reminder letter (as indicated above).

\section{Data analysis}

The examination of existing program data included comparisons between baseline and follow-ups (2-month and 5-month) among the program participant sample for relevant metrics including weight, BMI, total, HDL and LDL cholesterol, triglycerides, dietary fat intake, and exercise frequency. These comparisons were made using paired t-tests for statistical analyses. In addition, correlations were run between the 
Table I KSC/NASA physical activity status scale

Please check the box next to ONE of the following responses that best describes your exercise habits.

$0 \quad$ No regular exercise, no physical activity outside of office work

I No regular exercise, occasional walking or exertional activity

2 Rare regular exercise, some exertional activity, usually less than 30 minutes per week

3 Rare regular exercise, some exertional activity, usually more than 30 minutes per week but less than I hour per week

4 Occasional regular exercise, no more than 60 minutes of exercise per week

5 Regular exercise: weekly average of 30-60 minutes

6 Regular exercise: weekly average of $>I-3$ hours per week

7 Regular exercise: weekly average of $>3-6$ hours per week

8 Regular exercise: weekly average of $>6-9$ hours per week

9 Regular exercise: weekly average of $>9-1$ I hours per week

I0 Regular exercise: weekly average of $>$ II hours per week

difference in both total and LDL cholesterol and physical activity and dietary fat intake frequency scores at both 2-month and 5-month follow-ups using Pearson correlation coefficients.

\section{Results}

Data for the first three years of programming (May 2004May 2007) included 366 counseled participants out of 5550 participants total screened. This total however, is inflated due to the same employees participating in the monthly screening more than one time per year. The 366 participants were screened and counseled at some point during the threeyear data sample period. The counseled employees are only counseled once and are not entered more than once in the counseling data set.

Age and gender are the only demographics collected in the KSC CVD Risk Reduction Program. The average age for the 366 counseled participants was 49 years with $75 \%$ male and $25 \%$ female. At baseline screening, only $4 \%$ reported history of heart disease, $17 \%$ had history of high blood pressure, $36 \%$ had history of high cholesterol and only $5 \%$ had been diagnosed as diabetic. Only $8 \%$ were reported smokers, and $27 \%$ had family history of heart disease. Table 2 shows averages and comparison $\mathrm{p}$ values across screening and follow-ups for all measures. Table 2 also shows baseline characteristics separately for those participants who completed the two and five-month follow-ups.

Due to the voluntary nature of the KSC CVD Risk Reduction Program, participants are not required to complete follow-up screenings. From available program data, those participants who completed two-month follow-ups $(n=87)$, significant baseline to two-month followup comparisons included decreases in both systolic $(t=2.19$, $\mathrm{p}=0.03)$ and diastolic blood pressure $(\mathrm{t}=3.22, \mathrm{p}=0.002)$; total cholesterol $(\mathrm{t}=8.22, \mathrm{p}<0.0001)$; LDL cholesterol $(\mathrm{t}=9.55, \mathrm{p}<0.0001) ;$ and dietary fat intake $(\mathrm{t}=5.87$, $\mathrm{p}<0.0001)$ as well as a significant increase in exercise frequency $(\mathrm{t}=2.06, \mathrm{p}=0.04)$. For those who completed five-month follow-ups ( $\mathrm{n}=77)$, significant baseline to fivemonth follow-up comparisons included decreases in total cholesterol $(\mathrm{t}=6.77, \mathrm{p}<0.0001)$; LDL cholesterol $(\mathrm{t}=7.31$, $\mathrm{p}<0.0001)$; triglycerides $(\mathrm{t}=2.00, \mathrm{p}=0.05)$ and dietary fat intake frequency $(\mathrm{t}=4.35, \mathrm{p}<0.0001)$. From the correlations run among total and LDL cholesterol difference and physical activity and dietary fat intake frequency scores at two and five month follow-up, only the correlation between 2-month physical activity score and total cholesterol difference was significant $(r=0.35, \mathrm{p}<0.04)$.

\section{Discussion}

The purpose of this worksite program evaluation was to examine existing data from the Kennedy Space Center (KSC) CVD Risk Reduction Program to determine if CVD risk factors such as blood lipid levels and health behaviors such as dietary fat intake and exercise frequency are improved. Dietary fat intake was significantly reduced in both followups and exercise frequency was significantly increased in the first follow-up. Moreover, total and LDL cholesterol were also improved.

The mean baseline dietary fat intake frequency score for counseled employee participants was 41.51 (SD 5.80) indicating moderate regular consumption of high fatty foods on most days of the week. The decrease in fat intake frequency intake among participants to a lower frequency of saturated fat intake during the week (average score of 38.2) at follow-up could be a factor in the significant decreases in lipid values. According to Garg and Simha (2007), restriction of dietary saturated fat, trans-fat, and cholesterol can achieve substantial LDL cholesterol lowering. Moreover, recent ATP III guidelines emphasize intensive reduction of LDL or nonhigh-density lipoprotein cholesterol in patients at high risk of CHD through both therapeutic lifestyle intervention (dietary intake) and drug therapy (Brewer 2003).

The counseled participants' physical activity frequency increased significantly at the two-month follow-up from an average score of 4.74 (exercising only 30-45 minutes per week) to an average of score of 5.6 (exercising 1-2 hours per week). This difference means that participants went on average from "occasional regular exercise" to "regular 
Table 2 KSC CVD program measures

\begin{tabular}{|c|c|c|c|c|c|}
\hline \multicolumn{6}{|l|}{ Mean (SD) } \\
\hline Variable & Baseline $(n=366)$ & $2-\operatorname{mos} F / U(n=87)$ & p value & $5-\operatorname{mos} F / U(n=77)$ & p value \\
\hline$\overline{\text { Age }}$ & 49 years & 49 years & & 50 years & \\
\hline Gender & $75 \% \mathrm{M}, 25 \% \mathrm{~F}$ & $82 \% \mathrm{M}, 18 \% \mathrm{~F}$ & & $78 \% \mathrm{M}, 22 \% \mathrm{~F}$ & \\
\hline CVD history & $4 \%$ & $4 \%$ & & $3 \%$ & \\
\hline Blood pressure history & $17 \%$ & $16 \%$ & & $25 \%$ & \\
\hline High cholesterol history & $36 \%$ & $30 \%$ & & $26 \%$ & \\
\hline Diabetes history & $5 \%$ & $7 \%$ & & $4 \%$ & \\
\hline Smoker & $8 \%$ & $8 \%$ & & $7 \%$ & \\
\hline CVD family history & $27 \%$ & $24 \%$ & & $25 \%$ & \\
\hline Weight & $185.85(32.96)$ & I84.65 (27.91) & 0.240 & $182.49(28.65)$ & 0.678 \\
\hline BMI & $27.74(4.10)$ & $27.36(3.70)$ & 0.515 & $27.20(3.74)$ & 0.094 \\
\hline Systolic blood pressure & $128.28(I 5.20)$ & $126.32(12.35)$ & $0.03 I^{*}$ & $128.82(\mid 15.84)$ & 0.753 \\
\hline Diastolic blood pressure & $80.83(9.24)$ & $78.60(9.25)$ & $0.002 *$ & $80.44(7.77)$ & 0.426 \\
\hline Total cholesterol & $261.66(27.11)$ & $231.33(34.53)$ & $<0.000 I^{*}$ & $225.31(39.96)$ & $<0.000 I^{*}$ \\
\hline LDL cholesterol & $176.43(20.26)$ & | $44.82(3 \mid .49)$ & $<0.000 I^{*}$ & $140.10(39.26)$ & $<0.0001 *$ \\
\hline HDL cholesterol & $52.46(13.34)$ & $51.70(14.38)$ & 0.864 & $52.76(13.2 I)$ & 0.669 \\
\hline Triglycerides & $218.43(184.16)$ & $183.35(156.00)$ & 0.098 & 158.49 (87.19) & 0.049 \\
\hline **Dietary fat intake & $4 I .5 \mathrm{I}(5.80)$ & $38.21(4.66)$ & $<0.000$ I* & $39.17(5.13)$ & $<0.000 I^{*}$ \\
\hline ***Physical activity & $4.74(2.22)$ & $5.6(2.02)$ & $0.043^{*}$ & $5.26(2.24)$ & 0.347 \\
\hline
\end{tabular}

Notes: *Significant $(\mathrm{p}<0.05)$; **Dietary fat intake is the dietary fat intake frequency score; a higher score indicates more frequent consumption of dietary fat food sources in a given week; $* * *$ Physical activity is the physical activity frequency score; a higher score indicates more frequent physical activity performed in a given week.

exercise." This switch to regular exercise could also have contributed to the improvement in blood lipid values. From the correlational analyses, physical activity frequency was significantly related to total cholesterol difference at the two-month follow-up.

Most notably, the counseled participants had a significant average decrease in total cholesterol of over $30 \mathrm{mg} / \mathrm{dL}$ at two-month follow-up (11.5\% reduction) and an average decrease of over $36 \mathrm{mg} / \mathrm{dL}$ at 5 -month follow-up (14\% reduction). In terms of CHD risk reduction, just a $10 \%$ decrease in total cholesterol levels may result in an estimated 30 percent reduction in the incidence of CHD (CDC 2000). Even more impressive, the counseled participants had a significant average decrease in LDL cholesterol of over $32 \mathrm{mg} / \mathrm{dL}$ at twomonth follow-up (18\% reduction) and an average decrease of over $36 \mathrm{mg} / \mathrm{dL}$ at 5 -month follow-up ( $20 \%$ reduction). As mentioned earlier, the primary target of therapy for the latest ATP III guidelines remains LDL cholesterol. The guidelines state that therapeutic lifestyle changes consisting of diet, weight reduction, and increased physical activity should be included in all treatment regimens (Brewer 2003). For those employees at highest risk, a counseling intervention performed at the worksite such as the one evaluated here combined with drug therapy monitored by a primary care provider could greatly impact CHD risk.

This worksite intervention could be categorized into what Maston-Koffman and colleagues (2005) identified as a “promising practice." These researchers defined a promising practice as "an innovative worksite intervention that has field-based data showing positive cardiovascular health data for high blood pressure and cholesterol, but does not have controlled research to allow generalizable results." Since this evaluation consisted of an examination of existing program data and is not an actual research study, these results are, in fact, limited in generalizabilty. The outcomes of this program need to be weighed against the lack of a control group or random selection of participants. Also, dietary fat intake frequency questions are asked verbally in the phone counseling at baseline then submitted by participants via hardcopy at follow-ups. This difference in questionnaire administration could affect the participant self-reporting and hence affect the intake frequency results. Moreover, it is unknown if participants may have started drug therapy at screening follow-ups through their primary care provider off-center. At baseline, participants are asked if they are taking cholesterol-lowering medications and roughly $90 \%$ report not using drug therapy as they are unaware they have high cholesterol or have discontinued drug therapy (nonadherent). On an interesting note however, staff indicated that many participants did report to staff at counseling that they wanted to avoid starting medication therapy by making dietary and physical activity changes.

Duplication of this program in worksites and other settings where controlled research can be done is warranted. In addition 
to significant changes in lipids, dietary fat intake and exercise frequency, this counseling program produced interesting participant motivation observations. Within two to three days after sending CVD screening results to participants, the KSC program staff contacts high risk participants for phone counseling during the work shift. Staff consistently reported that participants are eager to discuss their recent lab results and do not mind taking a break from work to discuss or be asked dietary and physical activity questions. This participant eagerness could be explained by the effect of having just seen some less than favorable lab results. Participants seemed to be motivated to improve their lab values.

Therapeutic lifestyle interventions are certainly needed to reduce $\mathrm{CHD}$ and CVD risk and the worksite has proven to be an effective setting in which to deliver such interventions (Erfurt et al 1991; Erfurt and Holtyn 1991; Shi 1992; Gomel et al 1993; Larsen and Simons 1993; Fries et al 1994; Fielding et al 1995; Leutzinger et al 1995; Goetzel et al 1998; Ozminkowski et al 2000; Muto and Yamauchi 2001; Nilsson et al 2001). As mentioned earlier, few worksite studies and program evaluations or "promising practices" have reported in detail on the use and possible benefits of health education phone counseling for changing CVD risk factor behaviors following screening. The worksite program implementation strategies described here not only show signs of promising significant clinical results but was also observed to motivate dietary and physical activity changes. Though the program evaluation nature of these results are limited in generalizability, this counseling program is worthy of research testing in worksites and other settings where CVD screenings are performed.

\section{References}

[AHA] American Heart Association. 2007. Heart disease and stroke statistics - 2007 update. AHA, Dallas TX.

Brewer HB. 2003. New features of the National Cholesterol Education Program Adult Treatment Panel III lipid-lowering guidelines. Clin Cardiol, 26:III19-24.

[CDC] Centers of Disease Control and Prevention. 2000. State-specific cholesterol screening trends - United States, 1991-1999. MMWR, 49:750-5.

Erfurt JC, Foote A, Heirich MA. 1991. Worksite wellness programs incremental comparison of screening and referral alone, health education, follow-up counseling, and plant organization. Am J Health Promot, 5:438-48.

Erfurt JC, Holtyn K. 1991. Health promotion in small business what works and what doesn't work. J Occup Med, 33:66-73.

Fielding JE, Mason T, Knight K, et al. 1995. A randomized trial of the IMPACT worksite cholesterol reduction program. Am J Prevent Med, 11:120-3.

Fries JF, Harrington H, Edwards R et al. 1994. Randomized controlled trial of cost reductions from a health education program the California Public Employees' Retirement System (PERS) study. Am J Health Promot, 8:216-23.
Garg A, Simha V. 2007. Update on dyslipidemia. J Clin Endocrinol Metab, 92:1581-9.

Goetzel RZ, Hawkins K, Ozminkowski RJ, et al. 2003. The health and productivity cost burden of the "top 10" physical and mental health conditions affecting six large U.S. employers in 1999. J Occup Environ Med, 45:5-14

Goetzel RZ, Jacobson BH, Aldana SG, et al. 1998. Health care costs of worksite health promotion participants and non-participants. $J$ Occup Environ Med, 40:341-6.

Gomel M, Oldenburg B, Simpson JM, et al. 1993. Work-site cardiovascular risk reduction a randomized trial of health risk assessment, education, counseling, and incentives. Am J Public Health, 83:1231-8.

Greenland P, Knoll MD, Stamler J, et al. 2003. Major risk factors as antecedents of fatal and nonfatal coronary heart disease events. JAMA, 290:891-7.

Heaney C, Goetzel RZ. 1997. A review of health-related outcomes of multi-component worksite health promotion programs. Am J Health Promot, 11:290-307.

Jackson AS, Beard EF, Wier LT, et al. 1995. Changes in aerobic power of men ages $25 \pm 70$ y. Med Sci Sports Exerc, 27:113-20.

Jackson AS, Wier LT, Aers GW, et al. 1996. Changes in aerobic power of women, ages 20 to 64 y. Med Sci Sports Exerc, 28:884-91.

Kris-Etherton P, Eissenstat B, Jaax S, et al. 2001. Validation of the MEDFICTS, a dietary assessment instrument for evaluating adherence to total and saturated fat recommendations of the National Cholesterol Education Program Step 1 and Step 2 diets. J Am Diet Assoc, 101:81-6.

Larsen P, Simons, N. 1993. Evaluating a federal health and fitness program indicators of improving health. AAOHN J, 41:143-8.

Leutzinger J, Hawes C, Hunnicut D, et al. 1995. Predicting the ratio of benefit to cost in a cardiovascular disease-prevention program. Managing Employee Health Benefits, 1:1-10.

Matson-Koffman D, Goetzel RZ, Anwuri VV, et al. 2005. Heart healthy and stroke free: Successful business strategies to prevent cardiovascular disease. Am J Prev Med, 29(5S1):113-21.

Minino AM, Heron MP, Smith BL. 2006. Preliminary data for 2004 National Vital Statistics Reports; 54(19). Hyattsville, MD: National Center for Health Statistics.

Muto T, Yamauchi K. 2001. Evaluation of a multicomponent workplace health promotion program conducted in Japan for improving employees' cardiovascular disease risk factors. Prev Med, 33:571-7.

[NCEP] National Cholesterol Education Program. 2002. Third Report of the National Cholesterol Education Program (NCEP) Expert Panel on Detection, Evaluation, and Treatment of High Blood Cholesterol in Adults (Adult Treatment Panel III) Final Report. Circulation, 106:3143-421.

Nilsson PM, Klasson B, Nyberg P. 2001. Life-style intervention at the worksite - reduction of cardiovascular risk factors in a randomized study. Scand J Work Environ Health, 27:57-62.

Ozminkowski RJ, Goetzel RZ, Smith MW, et al. 2000. The impact of the Citibank, NA, health management program on changes in employee health risks over time. J Occup Environ Med, 42:502-11.

Pate RR, Pratt M, Blair SN, et al. 1995. Physical activity and public health. A recommendation from the Centers for Disease Control and Prevention and the American College of Sports Medicine. JAMA, 273:402-7.

Pelletier KR. 2001. A review and analysis of the clinical and costeffectiveness studies of comprehensive health promotion and disease management programs at the worksite 1998-2000 update. Am J Health Promot, 16:107-16.

Shi L. 1992. The impact of increasing intensity of health promotion intervention on risk reduction. Eval Health Prof, 15:3-25.

Wier LT, Ayers GW, Jackson AS, et al. 2001. Determining the amount of physical activity needed for long-term weight control. Intl J Obes, 25:613-21. 